\title{
Siting MSW landfills with a weighted linear combination methodology in a GIS environment
}

\author{
${ }^{1}$ A. Salman Mahini and ${ }^{2 *}$ M. Gholamalifard \\ ${ }^{1}$ Department of the Environment, Faculty of Fishery and Environment, University of Agriculture and Natural \\ Resources Sciences, Golestan Province, Gorgan, Iran \\ ${ }^{2}$ Department of the Environment, Faculty of Natural Resources and Marine Sciences, Tarbiat Modarres \\ University, Mazandran Province, Noor Iran \\ Received 26 June 2006; revised 15 August 2006; accepted 10 September 2006; available online 1 October 2006
}

\begin{abstract}
Landfill has been taken to the bottom of the hierarchy of options for waste disposal but has been the most used method for urban solid waste disposal. However, landfill has become more difficult to implement because of its increasing cost, community opposition, and more restrictive regulations regarding the siting and operation of landfills. Land is a finite and scarce resource that needs to be used wisely. Appropriate allocation of landfills involves the selection of areas that are suitable for waste disposal. The present work describes a type of multi-criteria evaluation (MCE) method called weighted linear combination (WLC) in a GIS environment to evaluate the suitability of the study region for landfill. The WLC procedure is characterized by full tradeoff among all factors, average risk and offers much flexibility than the Boolean approaches in the decision making process. The relative importance weights of factors are estimated using the analytical hierarchy process (AHP). In the final aggregated suitability image, zones smaller than 20 hectares are eliminated from the allocation process. Afterwards, the land suitability of a zone is determined by calculating the average of the suitability of the cells belonging to that zone, a process called zonal land suitability. The application of the presented method to the Gorgan city (Iran) indicated that there are 18 zones for landfill with their zonal land suitability varying from 155.426117 to 64.149024 . The zones were ranked in descending order by the value of their zonal land suitability. The results showed the use of GIS as a decision support system (DSS) available to policy makers and decision makers in municipal solid waste (MSW) management issues.
\end{abstract}

Key words: Landfill siting, weighted linear combination (WLC), geographic information system (GIS), zonal land suitability

\section{INTRODUCTION}

A municipal solid waste (MSW) management system uses one or more techniques of solid waste management such as landfilling, thermal treatment, biological treatment, recycling etc (Tchobanoglous, et al., 1993). Landfill is an essential part of any waste management system. Nowadays best practices for sustainable management of urban solid wastes involve integrated systems of waste management based on the following hierarchy: (i) waste minimisation in the production process; (ii) reuse of products to prolong their usefulness before entering the waste stream; (iii) recovery of materials and energy from the waste (e.g. recycling, composting, heat from combustion); and (iv) placing the remaining material in landfills (Leao, et al., 2004).

*Corresponding author, Email: mehdi_gholamalifard@yahoo.com Tel.: +98122 6253 102; Fax: +98122 6253499
Even if a combination of the above or other management techniques is utilized and policies of waste reduction and reuse are applied, the existence of a sanitary landfill is necessary to a MSW management system (Tchobanoglous et al., 1993). The use of landfill can be significantly reduced by diverting part of the generated waste to recovery operations, and also by minimising the generation of waste at source. However, landfills cannot be completely avoided. There is always some waste the generation of which cannot be avoided or for which there is no technology available for processing and recovery. In spite of the fact that landfill has been taken to the bottom of the hierarchy of options for waste disposal it has been the most used method for urban solid waste disposal. 
Landfill has become more difficult to implement because of its increasing cost, community opposition to landfill siting, and more restrictive regulations regarding the siting and operation of landfills. Land is a finite and scarce resource that needs to be used wisely. According to Lane and McDonald (1983) a successful landfill siting process involves evaluating the basic suitability of all available land for sanitary landfills as an aid in the selection of a limited number of sites for more detailed evaluation. Appropriate allocation of landfills involves the selection of areas that are suitable for waste disposal. With regards to waste management, site selection studies reported in the literature cover the allocation of urban solid waste landfills (Lane and McDonald, 1983; Chang and Wang, 1993; Lober, 1995; Siddiqui et al., 1996; Kao et al., 1997; Leao et al., 2001 and 2004; Themistoklis et al., 2005; Al-Jarrah and AbuQdais, 2006), hazardous solid waste centers (Canter, 1991 and Koo et al., 1991), and recycling operation facilities (Lober, 1995 and Hokkanen and Salminen, 1997), etc. The present work describes a type of multicriteria evaluation (MCE) method called weighted linear combination (WLC) in a GIS environment to evaluate the suitability of the outskirts of Gorgan city (Iran) for landfill. The presented method evaluates the entire study area using a grading scale from 0 to 255 (Byte Scale), where 0 denotes a site fully unsuitable for landfill while 255 shows a site optimum for landfill.

The utilization of zonal land suitability method is an innovation in landfill siting process.

\section{MATERIALS AND METHODS}

The study area stretches from $54^{\circ} 10^{\prime}$ to $54^{\circ} 45^{\prime}$ East and $36^{\circ} 44^{\prime}$ to $36^{\circ} 58^{\prime}$ North, comprising a region of approximately $1316 \mathrm{Km}^{2}$ (Fig. 1). The main land-cover types of the study area are dense broad-leaved forest, thinned out forest and pastures, needle-leaved woodlands, agriculture, water and residential areas. The economic growth in the area in the recent past has led to a large increase in population, driving dramatic urban expansion, land use change and increase in generation of solid wastes. Hence, for sustainable management of the solid waste produced, there is a need to locate suitable sites for future use. At present, there is a landfill site with an area approximately 11 ha in the west of city (Fig. 1). To meet a specific objective, it is frequently the case that several criteria will need to be evaluated. Such a procedure is called multi-criteria evaluation (Voogd, 1983 and Carver, 1991). Multi criteria evaluation (MCE) is most commonly achieved by one of three procedures (Eastman, 2001). The first involves Boolean overlay whereby all criteria are reduced to logical statements of suitability and then combined by means of one or more

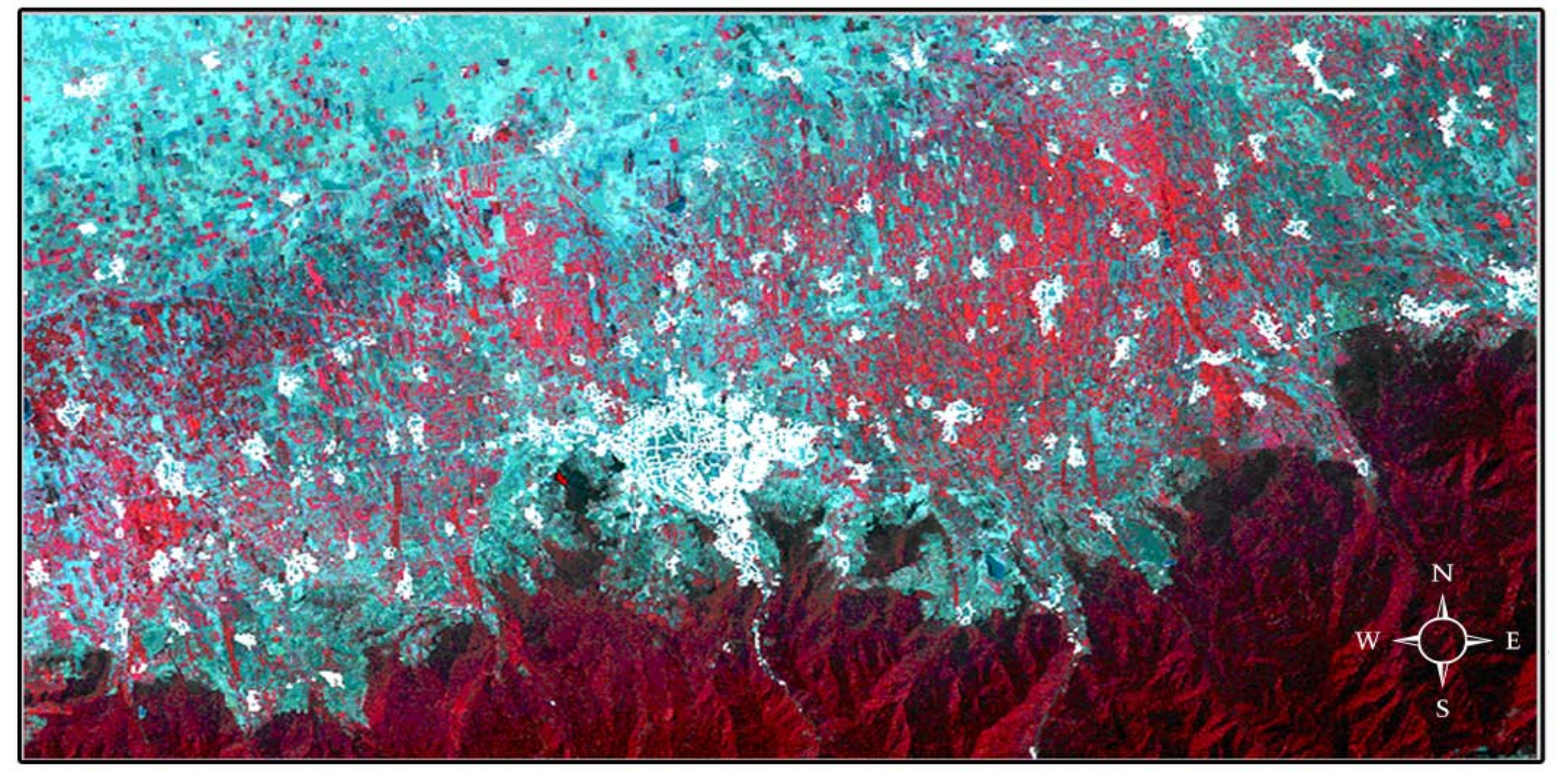

Fig 1: Color composite image of the study area, bands 2, 3, and 4 of ETM+ sensor of Landsat satellite, 30 $0^{\text {th }}$ July 2001, that white spots showing the residential areas 
logical operators such as intersection and union. The second is known as weighted linear combination wherein continuous criteria (factors) are standardized to a common numeric range, and then combined by means of a weighted average. The result is a continuous mapping of suitability that may then be masked by one or more Boolean constraints to accommodate qualitative criteria, and finally thresholded to yield a final decision. According to Hopkins (1977) the most prevalent procedure for integrating multi-criteria evaluation and multi-objective evaluation (MOE) in GIS for land suitability analysis is using a weighted linear combination approach. The WLC procedure allows full tradeoff among all factors and offers much more flexibility than the Boolean approaches. The third option for multi-criteria evaluation, known as an ordered weighted average (OWA) (Eastman and Jiang, 1996). This method offers a complete spectrum of decision strategies along the primary dimensions of degree of tradeoff involved and degree of risk in the solution.

First step in the methodology consists of development of a digital GIS database that includes spatial information. Because of the different scales upon which criteria are measured, it is necessary that factors be standardized before combination. In this research, a linear scaling method is applied using the minimum and maximum values as scaling points for standardization (Eq. 1.):

$$
X_{i}=\frac{\left(R_{i}-R_{\min }\right)}{\left(R_{\max }-R_{\min }\right)} * \text { standardized_range }
$$

where:

$\mathrm{R}=$ raw score,

$\mathrm{R}_{\text {min }}=$ Minimum score, and

$\mathrm{R}_{\text {max }}=$ Maximum score

It is provided the option of standardizing factors to a 0-255 byte scale. The primary issue in Multi-Criteria Evaluation is concerned with how to combine the information from several criteria to form a single index of evaluation. A criterion is some basis for a decision that can be measured and evaluated. Criteria can be of two kinds: factors and constraints. A factor is a criterion that enhances or detracts from the suitability of a specific alternative for the activity under consideration. A constraint serves to limit the alternatives under consideration constraints classify the areas into two classes: unsuitable (value 0 ) or suitable (value 1).
With a weighted linear combination, factors are combined by applying a weight to each followed by a summation of the results to yield a suitability map (Eastman, 2001) (Eq. 2.):

$$
\mathrm{S}=\sum \mathrm{W} \text { iX i }
$$

\section{Suitability}

$\mathrm{W}_{\mathrm{i}}=$ Weight of factor $\mathrm{i}$.

$\mathrm{X}_{\mathrm{i}}=$ criterion score of factor $\mathrm{i}$.

In presented method that Boolean constraints also apply, the procedure can be modified by multiplying the suitability calculated from the factors by the product of the constraints (Eq 3.)

$\mathrm{S}=\sum \mathrm{W} i \mathrm{X} i * \prod \mathrm{C} j$

$\mathrm{C}_{\mathrm{j}}=$ criterion score of constraint $\mathrm{j}$

II = product

The result of this MCE will be final aggregated suitability image. In the final aggregated suitability image, zones whose area is smaller than 20 hectares are eliminated from the allocation process. In the next step, the method determines the land suitability of a zone by calculating the average of the suitability of the cells belonging to a zone (Equation 4.):

$$
\mathrm{S}_{\mathrm{z}}=\frac{\sum(\mathrm{L} \text { i }) \mathrm{z}}{\mathrm{nz}}
$$

where:

$\mathrm{S}_{\mathrm{z}}=$ Zonal land suitability

$\left(L_{i}\right)_{z}=$ Local suitability of the cells $i$ belonging to the zone $\mathrm{z}$

$\mathrm{n}_{\mathrm{z}}=$ Number of cells of zones $\mathrm{z}$.

The results from the application of the presented methodology are zones for landfill with varying zonal land suitability. The zones are then ranked in descending order by the value of their zonal land suitability to facilitate the decision process. The evaluation criteria used in the present study are: Water permeability, depth of the underground water table, distance from rivers, distance from residential areas, and distance from roads, slope, and wind orientation.

Water permeability

This criterion classifies the whole area based on type 


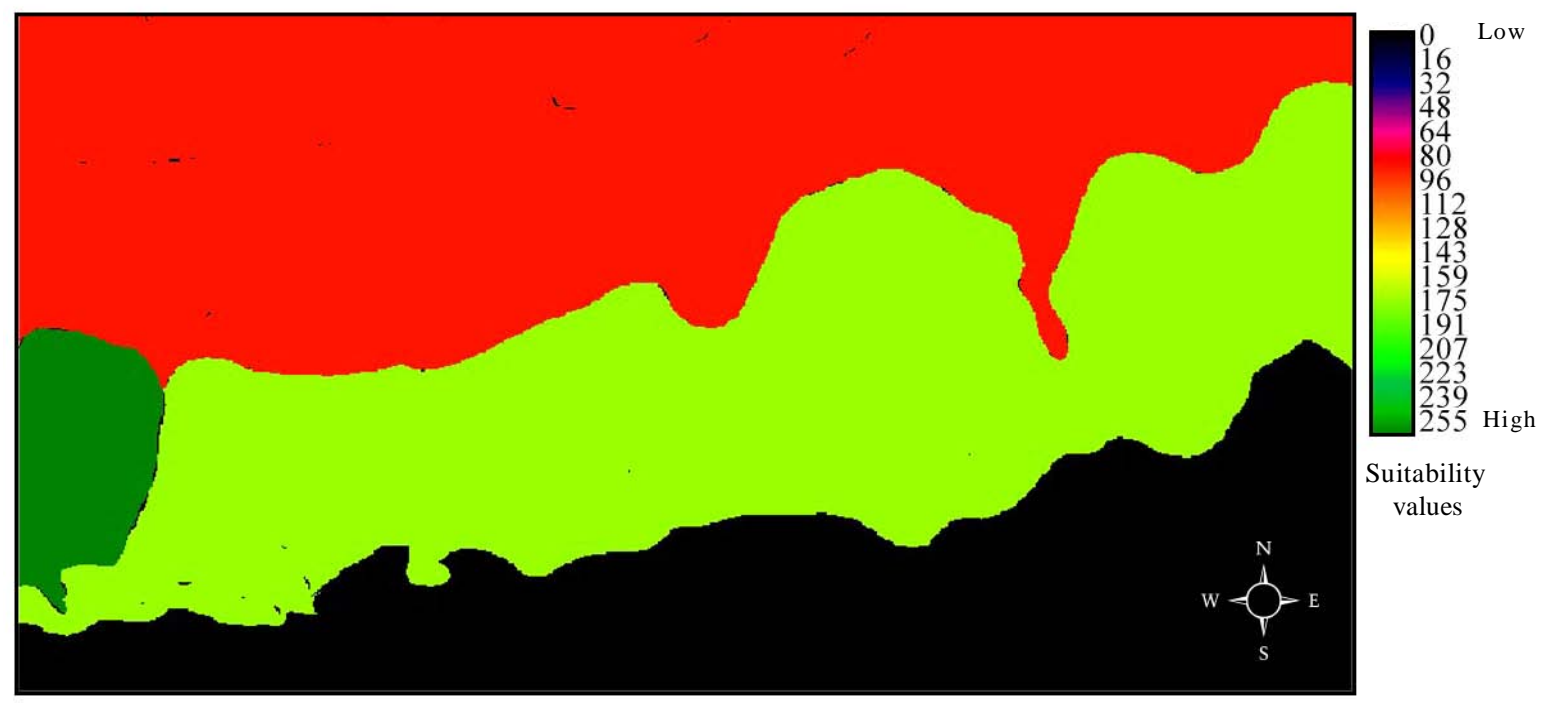

Fig. 2: Evaluation criteria: Water permeability (constraint and factor) in Gorgan

of soil and geological characteristics. It has obtained geological map of study area from National GeoDatabase of Iran (NGDIR) and the map of pedology (based on FAO's method) from soil and Water Research Institute of Iran. In the present work, four zones were designated, as shown in Fig. 2. Soils with bad drainage (haplic and calcic kastanozems, dystric cambisols, cambic podzols with karsts formations) were considered as undesirable areas for a landfill, having a grading value of 0 . The medium permeability zone (haplic solonchaks, gleyic solonchaks, eutric and mollic gleysols, gleyic solonchaks) having a grading value of 85 (low suitability). The low permeability zone (calcaric and eutric cambisol, dystric cambisols, gleyic cambisols, humic cambisols) having a grading value of 170 (medium suitability). Finally, the verylow permeability zone (calcic kastanozems, chromic luvisols, eutric cambisols, calcaric fluvisols, clayey soils and shale) were considered as optimal to site a landfill, having a grading value of 255 (High suitability).

\section{Depth of the underground water table}

This criterion classifies the whole area based on straight distance from groundwater level. These data obtained from Regional Water Organization of Golestan province. We suppose a linear monotoniacally increasing membership function for this criterion. Areas within $10 \mathrm{~m}$ distance from water table are considered unsuitable for allocating landfills (constraint). Land suitability increases linearly from 0 to 255, while the distance from water table increase from 10 to $50 \mathrm{~m}$. Suitabilityremains at the highest value in areas located further than $50 \mathrm{~m}$ (factor) (Figs. $3 \mathrm{a}$ and $\mathrm{b}$ ).

\section{Distance from rivers}

Figs. $4 \mathrm{a}$ and b illustrates the monotonically increasing linear membership function for distance from rivers in the evaluation of landfill suitability of the area. For deriving the rivers layer, we used visual image (ETM+ sensor of Landsat satellite, 30 $0^{\text {th. }}$ July 2001) interpretation and on-screen digitizing to generate individual vector layers that were transformed into raster layers with $20 \mathrm{~m}$ resolution. Rivers and the area within $200 \mathrm{~m}$ from them are considered unsuitable for allocating landfills (constraint). Land suitability increases linearly from 0 to 255 , while the distance from rivers increase from 200 to 1,000 meters. Suitability remains at the highest value in areas located further than $1,000 \mathrm{~m}$.

\section{Distance from residential areas}

Another evaluation criterion is related to the distance from residential areas. Based on the study developed by Lober and Green (1994) and Lober (1995), it was considered that public opposition decays exponentially with increasing distances. Suitability, in turn, increases with decreasing public opposition. Landsat ETM+ scene of the Gorgan city covering around $1316 \mathrm{Km}^{2}$ were selected for this study. The scenes which dated $30^{\text {th. }}$ July 2001 were imported into Idrisi 32 software (Eastman, 2001), geo-registered to the other layers and re-sampled to 20 meters resolution. Then the scene was classified using knowledge from the area and Maximum Likelihood supervised classification method. Seven classes were identified: water, agriculture, fallow lands, built up areas, dense broad leaved forest, thin 
Siting MSW landfills...
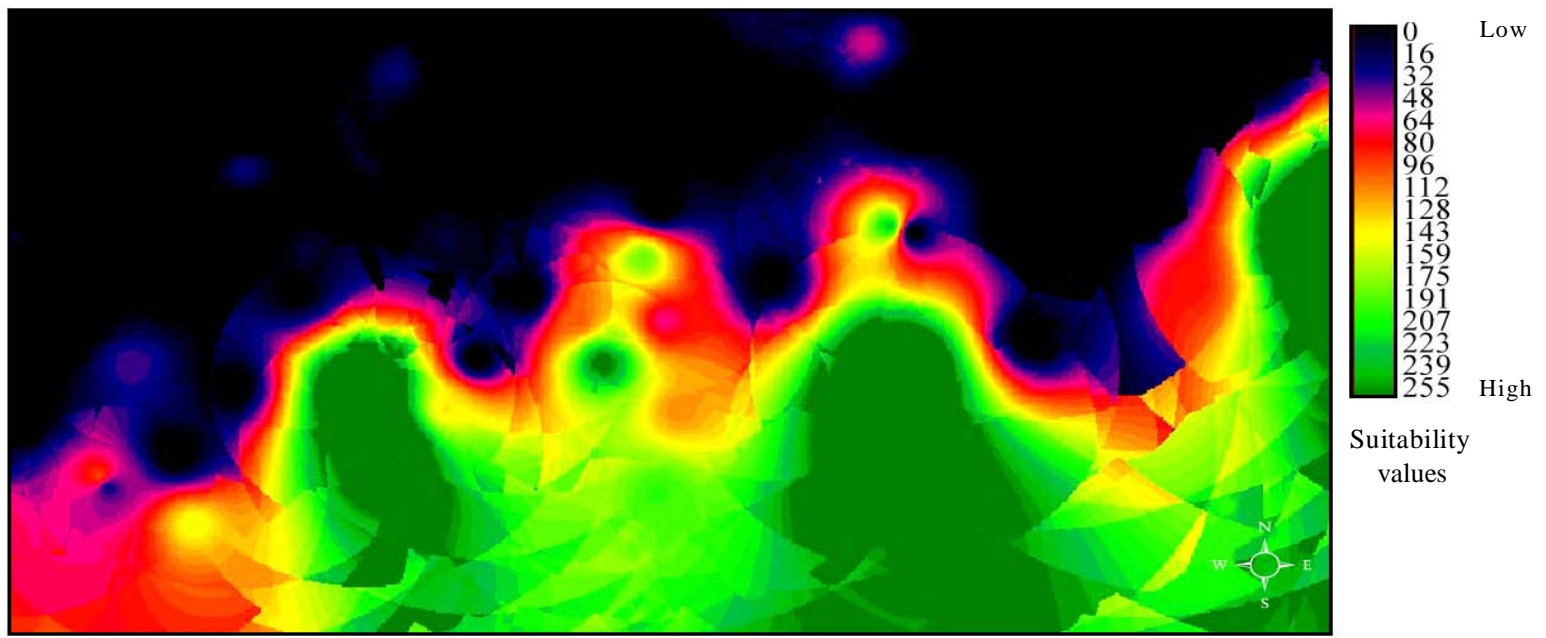

Suitability

values

Fig. 3 b: Depth of the underground water table in Gorgan

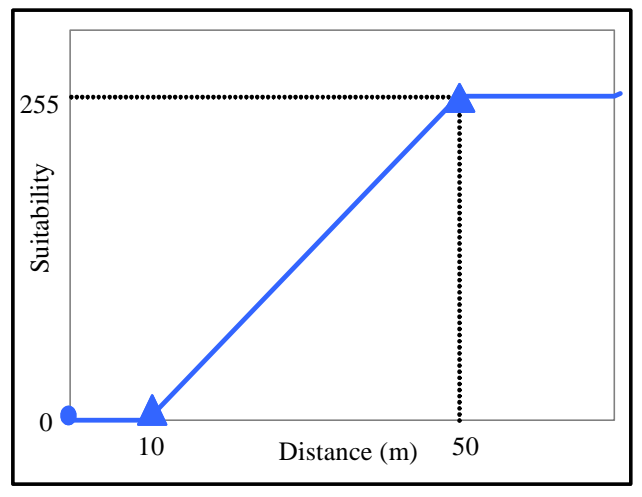

Fig. 3a: Evaluation criteria: Depth of the underground water table (constraint and factor)

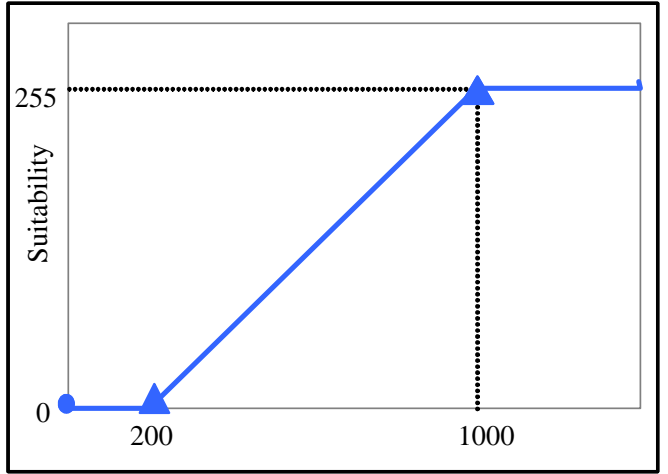

Fig. 4 a: Evaluation criteria: Distance from rivers (constraint and factor)

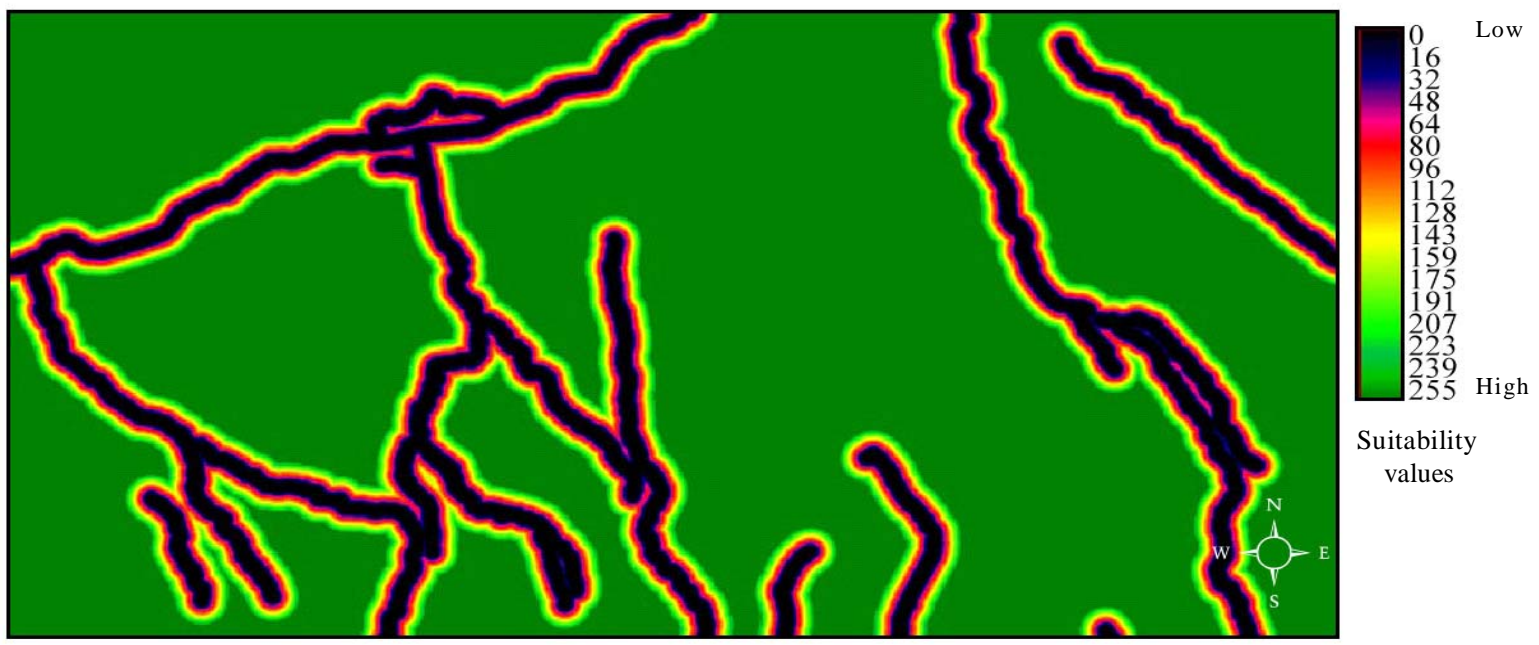

Fig 4 b: Distance from rivers in Gorgan 
detailed land cover classifications into a binary urban / non urban map. Residential areas and areas within forest, pastures and needle leaved woodlands. The urban extent was derived from reclassification of these1,000 $\mathrm{m}$ of them are considered unsuitable for allocating landfills (constraint). Land suitability increases linearly from 0 to 255, while the distance from residential areas increase from 1000 to 10,000 meters. Suitability remains at the highest value in areas located further than 1,000 meters (factor) (Figs. 5 a and b).

\section{Distance from roads}

Figs. 6 a and b illustrates the criterion related to the distance from road network. For deriving the roads layer, we used visual image (ETM+ sensor of Landsat satellite, $30^{\text {th. }}$ July 2001) interpretation and on-screen digitizing to generate individual vector layers that were transformed into raster layers with $20 \mathrm{~m}$ resolution. All roads and the areas within $100 \mathrm{~m}$ of them are considered unsuitable for the allocation of landfills. In this case, the suitability decreases as the distance from road network increases. This results in longer distances to be less suitable as transportation costs increase. Here, we supposed that the suitability decreases linearly with distance. Land suitability decreases from 255 to 0, while the distance from roads increases from $100 \mathrm{~m}$ to 1000 (factor). The areas located further than $1000 \mathrm{~m}$ from roads are considered unsuitable. The topographical features of study have been illustrated in Fig. 7-b. It describes the constraint and factor functions for landfill suitability evaluation associated with topography. We geo-registered and re-sampled a 10 meter DEM of the area obtained from National Cartographic Center of Iran to 20 meters resolution using Idrisi32 software (Eastman, 2001).

Then, we derived the slope layer from the DEM layer. Areas sloped higher than 20\% are considered unsuitable for allocating landfills (constraint). Land suitability decreases from 255 to 0 , while the slope increases from $0 \%$ to $20 \%$ (factor) (Fig. $7-a, b$ ).

\section{Wind orientation}

Based on records from Meteorological Organization of Iran, the most frequently encountered winds in Gorgan city are the west, northwest and southwest

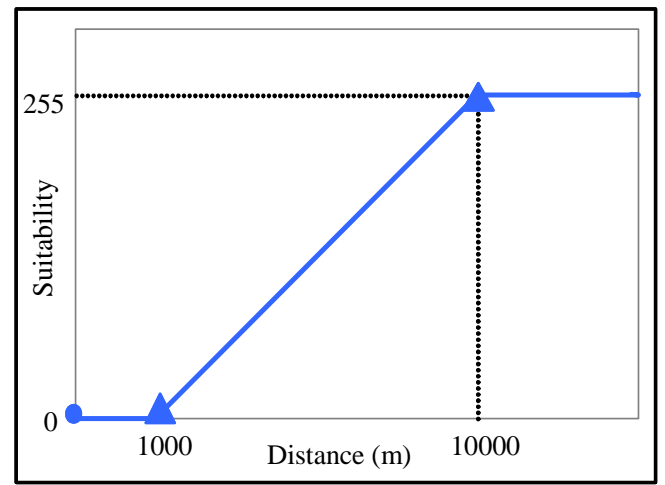

Fig. 5 a: Evaluation criteria: Distance from residential areas (constraint amd factor)

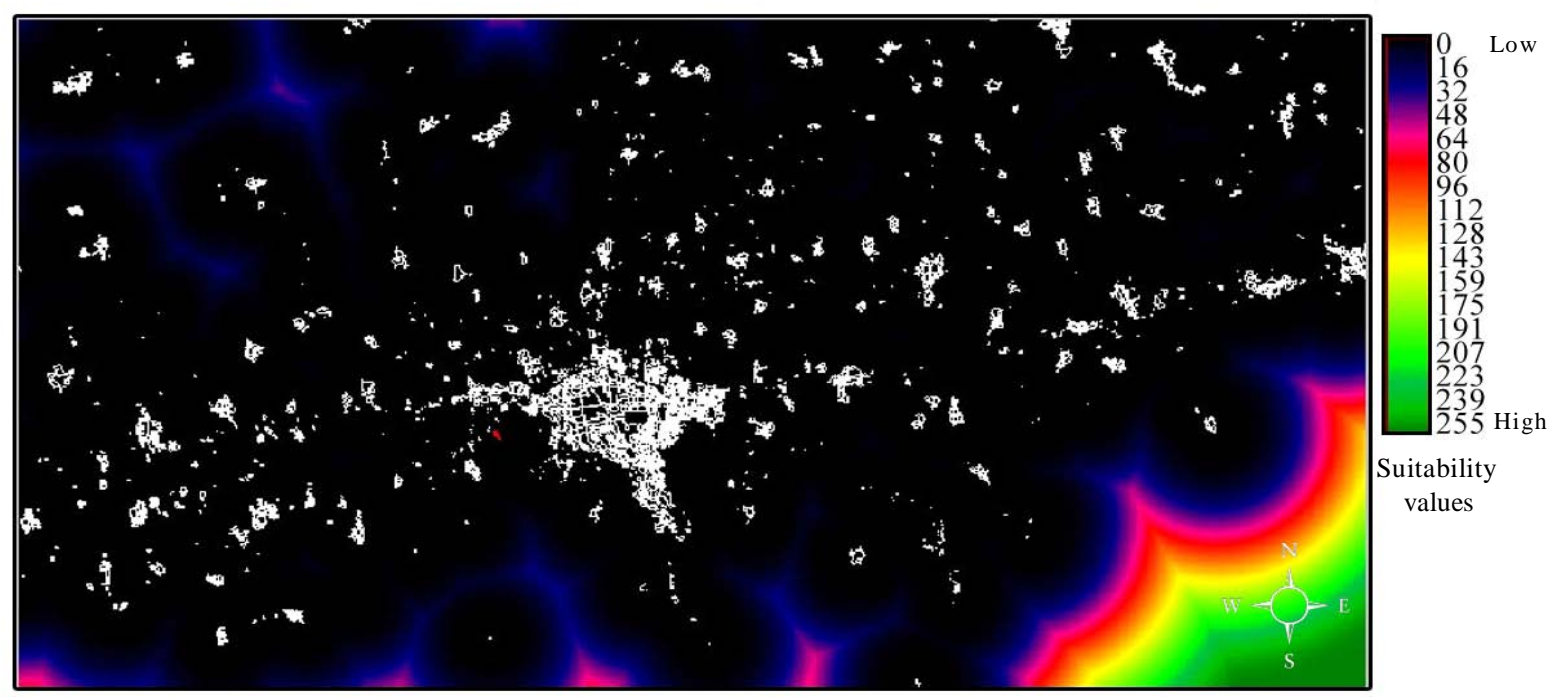

Fig. 5 b: Distance from residential areas. White spots show the residential areas 
Siting MSW landfills...

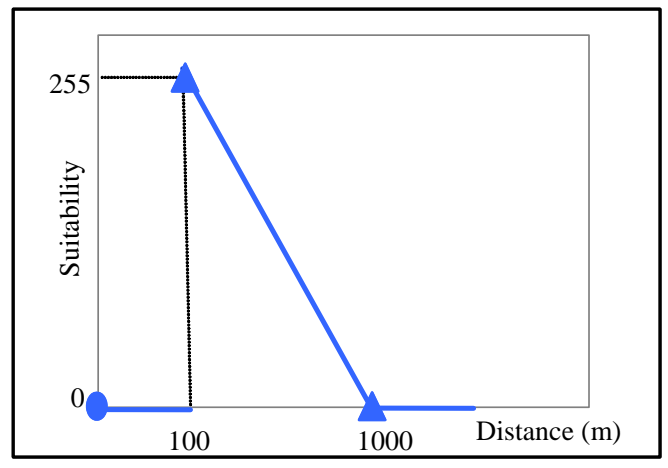

Fig. 6 a: Evaluation criteria: Distance from roads (constraint and factor)

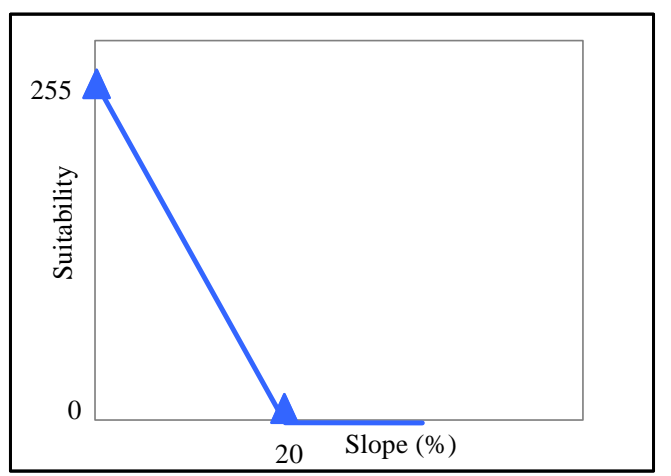

Fig. 7 a: Evaluation criteria: Slope (constraint and factor)

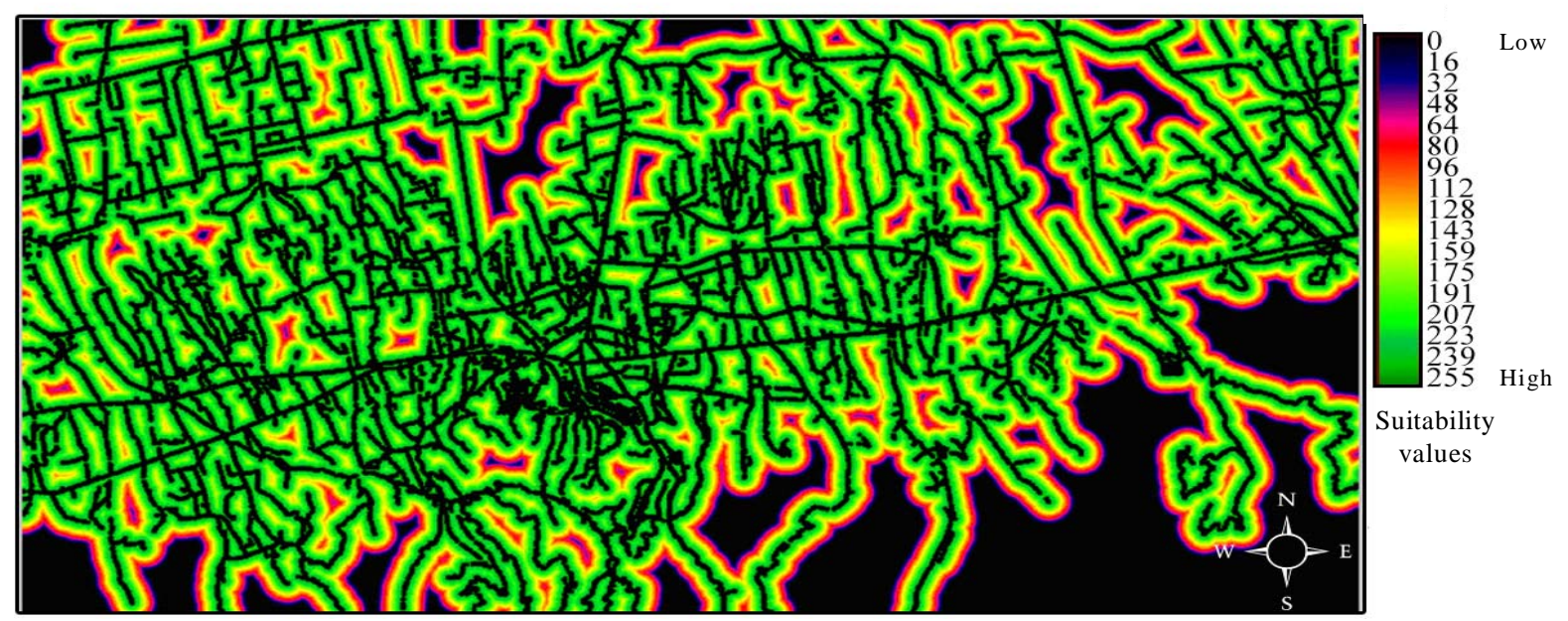

Fig. 6 b: Distance from roads in Gorgan
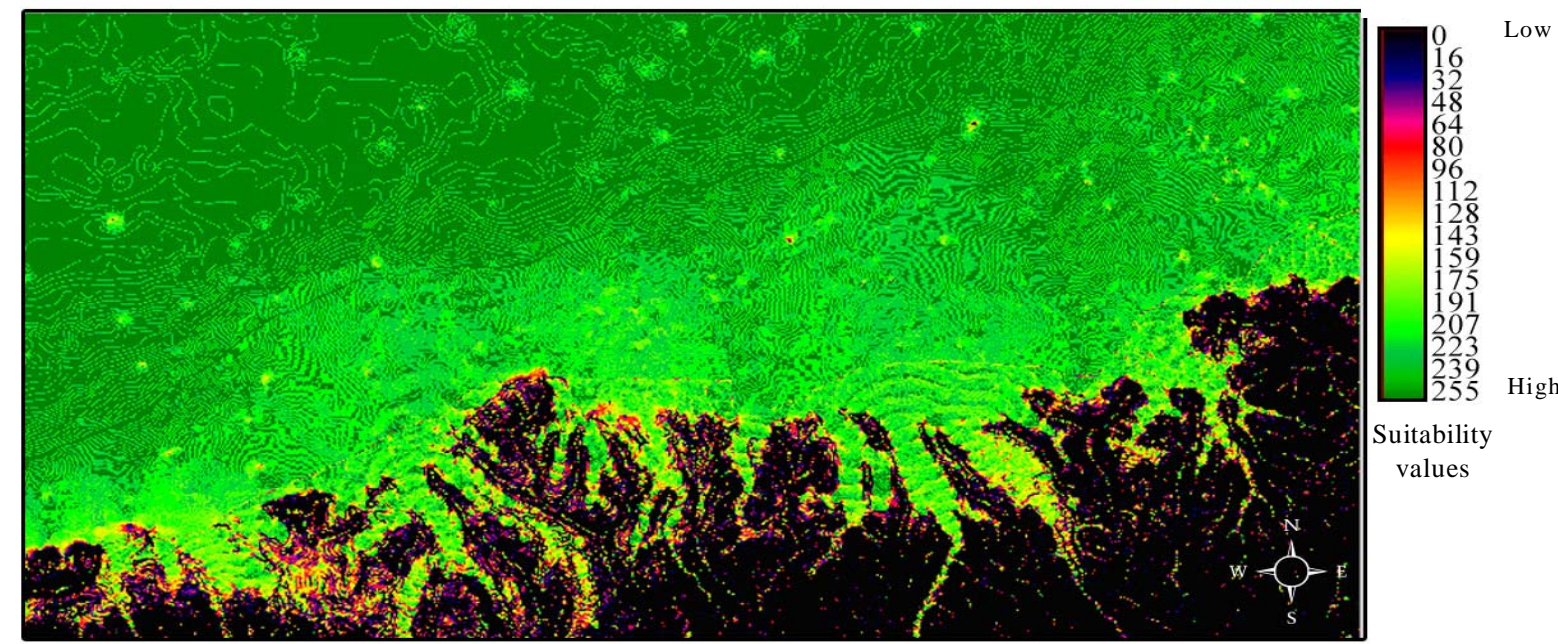

Fig. 7 b: Slope formation in Gorgan 
winds. Because the study area is mainly flat, Wind orientation acts only as a constraint around Gorgan city where areas within 5000 meters of North, West and South are considered unsuitable for the allocation of landfills. The last step in the presented methodology is the application of the WLC method, shown in Equation (3). The evaluation criteria are in a raster GIS format with a 20m resolution and UTM_40n projection. In the context of criterion weights, a wide variety of techniques exist for the development of weights. The technique used here and implemented in Idrisi32 software (Eastman, 2001) is that of pairwise comparisons developed by Saaty (1977) in the context of a decision making process known as the Analytical Hierarchy Process (AHP). In the procedure for MultiCriteria Evaluation using a weighted linear combination (WLC), it is necessary that the weights sum to one. In Saaty's technique, weights of this nature can be derived by taking the principal eigenvector of a square reciprocal matrix of pairwise comparisons between the criteria. The comparisons concern the relative importance of the two criteria involved in determining suitability for the stated objective. Ratings are provided on a 9-point continuous scale in three parts: less important, equally (1) and more important. Since the matrix is symmetrical, only the lower triangular half actually needs to be filled. The procedure then requires that the principal eigenvector of the pairwise comparison matrix be computed to produce a best fit set of weights. These weights will sum to one, as is required by the weighted linear combination procedure. Since the complete pairwise comparison matrix contains multiple paths by which the relative importance of criteria can be assessed, it is also possible to determine the degree of consistency that has been used in developing the ratings. Saaty (1977) indicates the procedure by which an index of consistency, known as a consistency ratio. The consistency ratio (CR) indicates the probability that the matrix ratings were randomly generated. Saaty indicates that matrices with CR ratings greater than 0.10 should be re-evaluated (Table 1).

The result of the MCE applied here is an aggregated suitability image. This is a continuous image that contains a wealth of information concerning overall suitability for every location. There are several methods for site selection using a continuous image of suitability. In present paper another post aggregation constraint has been applied such that suitable areas less than 20 hectares have been eliminated. In the next step, the land suitability of a zone is determined by Equation 4. The application of the presented methodology resulted in zones for landfill with their zonal land suitability varying from $0-255$. Then the zones were ranked in descending order by the value of their zonal land suitability.

Table 1: AHP weight derivation of evaluation criteria

\begin{tabular}{cccccccc}
\hline & 1 & 2 & 3 & 4 & 5 & 6 & weights \\
\hline 1 & 1 & & & & & & 0.0617 \\
2 & $1 / 3$ & 1 & & & & & 0.0370 \\
3 & 3 & 3 & 1 & & & & 0.1056 \\
4 & 5 & 7 & $1 / 3$ & 1 & & & 0.3194 \\
5 & 5 & 5 & 1 & 3 & 1 & & 0.3077 \\
6 & 3 & 5 & $1 / 3$ & 3 & $1 / 3$ & 1 & 0.1686 \\
\hline
\end{tabular}

Consistency ratio $=0.05$, Consistency is acceptable.

The numbers at the decision criteria are: (1) Water permeability, (2) Depth of the underground water table, (3) Distance from rivers, (4) Distance from residential areas, (5) Distance from roads, (6) Slope.

\section{RESULTS}

The application of the presented methodology in the Gorgan city (Iran) indicated that there are 18 zones for landfill that their zonal land suitability varied from 155.426117 to 64.149024 (Fig. 8) and (Table 2). The research was conducted to evaluate the basic suitability of all available land for sanitary landfills as an aid in the selection of a limited number of sites for more detailed evaluation. It is important to emphasize at this stage that the actual availability of land for landfill could be significantly lower than the amount shown in the Table 2. A more complete land evaluation should consider other characteristics, such as more detailed analysis of current and future land uses, economic use and price of the land and so on. Because most of these criteria demand intensive field surveying, the process is implemented after small areas have been selected by general criteria. The analysis of the level of suitability of the zones selected along the allocation process shows the little available land suitable for landfill. This situation indicates that the areas to be used for landfill are going to become progressively less accessible. This has consequences on the costs of the waste disposal system, as well as on the risks for the environment and the community. Low suitability results, for example, from the use of areas whose soil presents low suitability, or areas near the rivers. 
Table 2: Zonal land suitability and area of 18 zones for landfill ranked in descending by the value of zonal land suitability

\begin{tabular}{|c|c|c|c|c|c|}
\hline $\begin{array}{c}\text { Number of } \\
\text { zones }\end{array}$ & $\begin{array}{l}\text { Minimum } \\
\text { suitability }\end{array}$ & $\begin{array}{l}\text { Maximum } \\
\text { suitability }\end{array}$ & $\begin{array}{c}\text { Total } \\
\text { suitability }\end{array}$ & Area (ha.) & $\begin{array}{c}\text { Average(zonal) land } \\
\text { suitability }\end{array}$ \\
\hline 1 & 142 & 162 & 90458 & 23.2854617 & 155.426117 \\
\hline 2 & 136 & 169 & 123346 & 31.9674982 & 154.375469 \\
\hline 3 & 127 & 165 & 105105 & 28.2866348 & 148.663366 \\
\hline 4 & 128 & 155 & 140077 & 38.8491123 & 144.260556 \\
\hline 5 & 92 & 169 & 361351 & 102.1839679 & 141.484338 \\
\hline 6 & 89 & 168 & 190362 & 54.6528192 & 139.357247 \\
\hline 7 & 114 & 161 & 255207 & 73.6572768 & 138.624117 \\
\hline 8 & 111 & 162 & 338971 & 101.0236957 & 134.245941 \\
\hline 9 & 116 & 154 & 75293 & 22.5252834 & 133.735346 \\
\hline 10 & 93 & 168 & 675239 & 207.6887147 & 130.078790 \\
\hline 11 & 95 & 161 & 396163 & 121.9085944 & 130.017394 \\
\hline 12 & 104 & 157 & 80403 & 24.8058184 & 129.682258 \\
\hline 13 & 87 & 145 & 80095 & 27.6464847 & 115.91172 \\
\hline 14 & 74 & 147 & 57110 & 20.2447485 & 112.865613 \\
\hline 15 & 65 & 155 & 271272 & 108.3454131 & 100.174298 \\
\hline 16 & 24 & 152 & 477351 & 204.4079451 & 93.433353 \\
\hline 17 & 42 & 129 & 79193 & 45.7307264 & 69.285214 \\
\hline 18 & 29 & 92 & 154535 & 96.3826071 & 64.149024 \\
\hline
\end{tabular}

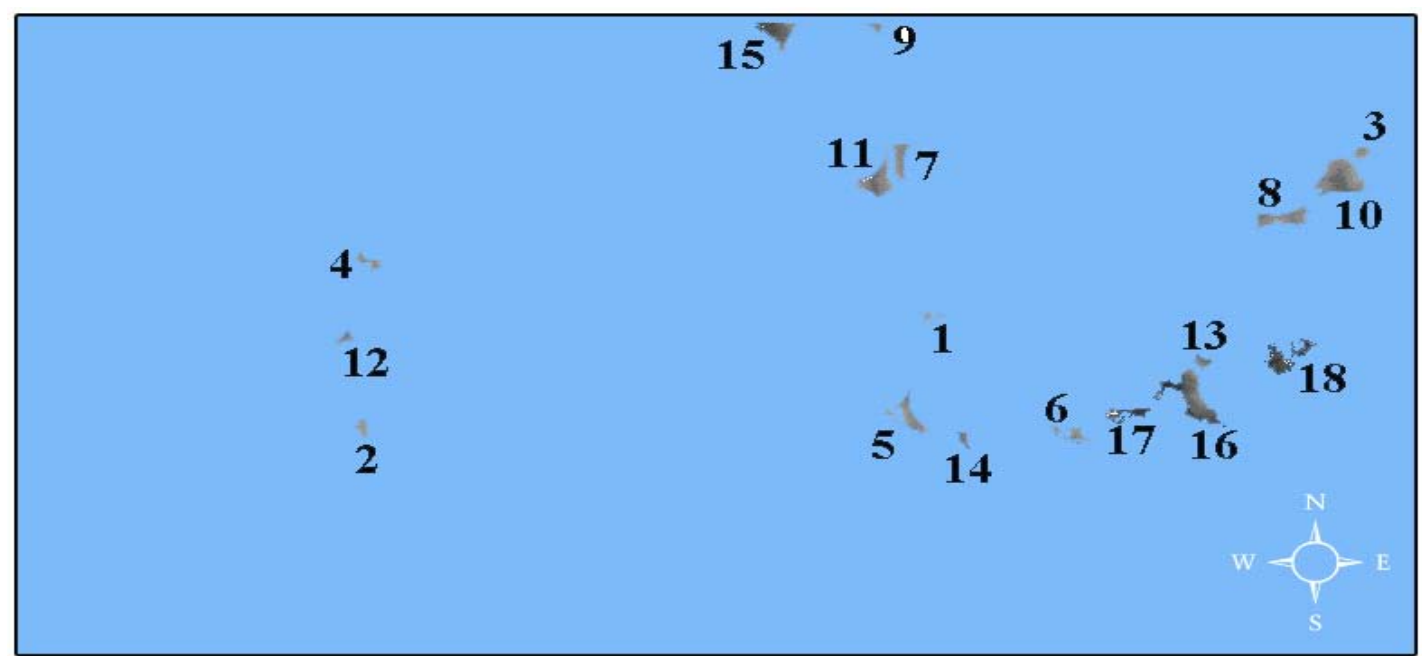

Fig. 8: 18 zones for landfill ranked in descending order by the value of zonal land suitability

In such cases, it is necessary to use more sophisticated operations and advice to assure environmental protection, which leads in turn to higher costs. Also, low suitability can result from the use of land close to residential areas, which might lead to strong public opposition.

\section{DISCUSSIONAND CONCLUSION}

Planning and management are based on generic problem solving. They begin with problem definition and description, and then turn to various forms of analysis, which might include simulation and modeling, and finally move to prediction and thence to prescription or design, which often involves the evaluation of alternative solutions to the problem (Batty and Densham, 1996). According to RubensteinMontano and Zandi (2000), modeling tools form the majority of approaches developed to assist decisionmakers with planning activities. The method described in the present paper combines the evaluation abilities of MCE method and the analytical tools of GIS and show the use of GIS as a decision support system (DSS). The first step of the model assesses the availability of 
land for waste disposal by combining all the criterions (constraint and factors) for landfill plus the minimum area requirement constraint (20 he). The relative importance weights of factors are estimated using the analytical hierarchy process (AHP). Initially, the land evaluation is performed on a cell by cell basis. The suitability of each cell for landfill is calculated by means of weighted linear combination (WLC) of multiple criteria in raster GIS. The WLC procedure allows full tradeoff among all factors. The amount any single factor can compensate for another is, however, determined by its factor weight. In terms of relative risk, a Boolean MCE that uses the AND operation is essentially a very conservative or risk averse operation, and that OR operation is extremely risk taking. These are the extreme on a continuum of risk. WLC lies exactly in the middle of this continuum. WLC, then, is characterized by full tradeoff and average risk. The weighted linear combination aggregation method offers much more flexibility than the Boolean approach. It allows for criteria to be standardized in a continuous fashion, retaining important information about degree of suitability. It also allows the criteria to be differentially weighted and to trade off with each other. While a variety of standardization and aggregation technique are important to explore for any multi-criteria problem, they result in images that show the suitability of location in the entire study area. The WLC approach results in continuous suitability image that makes selecting specific sites for landfill, or any other allocation, problematic. In the WLC approach, site suitability was clearly defined and the only problem for site selection was one of contiguity. With a continuous result, there is first the problem of deciding what locations should be chosen from the set of all locations, each of which has some degree of suitability. Only after this is established can the problem of contiguity be addressed. This was addressed by adding the post-aggregation constraint that suitable sites must be at least 20 hectares in size. The model then calculated the suitability for landfill for each zone. This zonal suitability is obtained by calculating the average of the suitability of all cells belonging to each zone. In the final step, zones were ranked in descending order by the value of their zonal land suitability. From among the zone, managers of the city can choose the best in terms of availability, price and so forth such a sustainable environmental management is achieved.
Results can be useful for policy makers and decisionmakers in Gorgan city. Finally, it must be noted that the presented method is a only tool to aid decision makers; it is not the decision itself.

\section{ACKNOWLEDGEMENT}

The study presented here is part of the thesis in partial fulfillment of the requirements for the degree of M.Sc. in Tarbiat Modarres University (T.M.U.) of Iran. First and foremost, the first author would like to thank his supervisor Dr. Abdolrassoul Salman Mahini for the high quality of his academic advice and direction and for continuing encouragement and support in the preparation of the thesis. The authors extend their appreciation for the support provided by the authorities of the Tarbiat Modarres University in funding the study and presenting its results in the International Journal of Environmental Science and Technology (IJEST).

\section{REFERENCES}

Al-Jarrah, O. and Abu-Qdais, H., (2006). Municipal solid waste landfill siting using intelligent system. Waste management, In Press.

Batty, M. and Densham, P. J., (1996). Decision support, GIS, and urban planning. Available at: http://www.geog.ucl.ac.uk/ $\sim$ pdensham/SDSS/s_t_paper.html

Canter, L. W., (1991). Environmental impact assessment for hazardous waste landfills. J. Urban Plan. Develop., 117 (2), 59-76.

Carver, S., (1991). Integrating multi-criteria evaluation with geographical information systems. Int. J. Geographic. Info. Sci., 5, 321-339.

Chang, N. B. and Wang, S. F., (1993). A locational model for the site selection of solid waste management facilities with traffic congestion constraints. J. Civil Eng. Sys., 11, 287306.

Eastman, R. J., (2001). Guide to GIS and Image processing, Vo.2. Clark university, USA. 144.

Eastman, R. J., (2001). Idrisi 32, Release 2. Tutorial. Clark university, USA. 237.

Eastman, J. R., and Jiang, H., (1996). Fuzzy measures in multicriteria evaluation, proceedings, $2^{\text {nd. }}$ International Symposium on Spatial Accuracy Assessment in Natural Resources and Environmental Studies, May 21-23, Fort Collins, Colorado, 527-534.

Hokkanen, J. and Salminen, P., (1997). Locating a waste treatment facility by multi-criteria analysis. J. M. Crit. Dec. Ana., 6, 175-184.

Hopkins, L. D., (1977). Methods for generating land suitability maps: a comparative evaluation. J. Am. Inst. Plan., 43 (4), 386-400.

Kao, J. J., Lin, H. Y. and Chen W. Y., (1997). Network geographic information system for landfill siting. Waste Manag. Res., 15, 239-253. 
Koo, J. K., Shin, H. S. and Yoo, H. C., (1991). Multi-objective siting planning for a regional hazardous waste treatment centre. Waste Manag. Res., 9, 205-218.

Lane, W. N. and McDonald, R. R., (1983). Land suitability analysis: landfill siting. J. Urban Plan. Develop., 109 (1), 50-61.

Leao, S., Bishop, I. and Evans, D., (2001). Assessing the demand of solid waste disposal in urban region by urban dynamics modeling in a GIS environment. Resources, Conserv. Recyc., 33, 289-313.

Leao, S., Bishop, I. and Evans, D., (2004). Spatial-Temporal model for demand and allocation of waste landfills in growing urban region. Computers, Environ. Urban Sys., 28, 353385.

Lober, D. J. and Green, D. P., (1994). NIMBY or NIABY: a logit model of opposition to solid waste-disposal facility siting. J. Environ. Manag., 40, 33-55.

Lober, D. J., (1995). Resolving the siting impasse: modelling social and environmental locational criteria with a geographic information system. J. Am. Plan. Assoc., 61 (4), 482-495.
Rubenstein-Montano, B. and Zandi, I., (2000). An evaluative tool for solid waste management. J. Urban Plan. Develop., 126 (3), 119-135.

Saaty, T. L., (1977). A scaling method for priorities in hierarchical structures. J. Math. Psycho., 15, 234-281.

Siddiqui, M. Z. Everett, J. W. and Vieux, B. E., (1996). Landfill siting using geographic information systems: a demonstration. J. Environ. Eng., 122 (6), 515-523.

Tchobanoglous, G., Theisen, H. and Vigil, S. A., (1993). Integrated solid waste management: Engineering principles and management issues. McGrow-Hill, New York, USA.

Themistoklis, D. K., Dimitrois, P. K. and Constantinos, P. H., (2005). Siting MSW landfills with a spatial multiple criteria analysis methodology. Waste manag., 25, 818-832.

Voogd, H., (1983). Multicriteria evaluation for urban and regional planning. Pion, Ltd., London.

\section{AUTHOR(S) BIOSKETCHES}

Salman Mahini, A., Assistant professor, Department of Environment, Faculty of Fishery and Environment, University of Agriculture and Natural Resources Sciences, Golestan Province, Gorgan, Iran. Email:a_mahini@yahoo.com

Gholamalifard, M., M.Sc. Student, Department of the Environment, Faculty of Natural Resources and Marine Sciences, Tarbiat Modarres University, Mazandran Province, Noor, Iran.

Email:mehdi_gholamalifard@yahoo.com

\section{This article should be referenced as follows:}

Salman Mahini, A. and Gholamalifard, M., (2006). Siting MSW landfills with a weighted linear combination (WLC) methodology in a GIS environment. Int. J. Environ. Sci. Tech., 3 (4),435- 